\title{
A consolidação do regime de cooperação e a criação de um sistema nacional de educação: da atualidade do manifesto dos pioneiros de 1932 ao novo plano nacional de educação
}

\author{
The consolidation of the cooperation arrangements and the creation of a \\ national education system: the relevance of the 1932 pioneers manifesto of the \\ new national education plan \\ La consolidación de el régimen de cooperación y la creación de un sistema \\ nacional de educación: la relevancia del manifiesto del pioneros 1932 y del \\ nuevo plan nacional de educación \\ CÉLIO DA CUNHA \\ LUCIANA CORDEIRO LIMEIRA
}

\begin{abstract}
Resumo: A garantia e a efetivação do direito à educação, a organização de um Sistema Nacional de Educação e a criação de fundos para seu financiamento são temas muito recorrentes na análise contemporânea de políticas públicas. No entanto, tais temáticas já constavam no documento intitulado Manifesto dos Pioneiros da Educação Nova de 1932. Com a Constituição Cidadã de 1988, o regime de cooperação foi instituído para garantir a distribuição de recursos financeiros aos entes federados como também entre eles, e, assim, efetivar direitos sociais. Este artigo tem por objetivo apresentar algumas reflexões acerca da consolidação do regime de cooperação e sua repercussão no levantamento e no uso dos fundos contábeis para a educação e para a plena realização do Plano Nacional de Educação (PNE).
\end{abstract}

Palavras-chave: Regime de Cooperação; Manifesto dos Pioneiros da Educação Nova; Financiamento da Educação.

Abstract: The guarantee and the realization of the right to education, the
organization of a National System of Education and the creation of funds for its
financing are recurrent themes in contemporary public policy analysis. However,
such issues were already contained in the document entitled New Education
Pioneers Manifest from 1932. With the Citizen Constitution of 1988, the
cooperation scheme was set up to ensure the distribution of financial resources
to federal entities (and between them) and thus effect social rights. This article
aims to present some reflections on the consolidation of the cooperation
procedure and its consequences on the collection and use of financial funds
for education and the completion of the National Education Plan (NEP).

Keywords: Cooperation Scheme; New Education Pioneers Manifest; Education Funding.

Resumen: Garantizar y lograr el derecho a la educación, la organización de un Sistema Nacional de Educación y la creación de fondos para financiarlas son 
temas muy recurrentes em el análisis de las políticas públicas em la actualidad. Sin embargo, estas cuestiones ya estaban contenidos em el documento titulado Manifiesto de los Pioneros de la Nueva Educación, 1932. Com la Constitución Ciudadano de 1988, del programa de cooperación se estableció para garantizar la distribución de los recursos financieros a las agencias federales, y entre ellos, y por lo tanto efectuar derechos sociales. Este artículo tiene como objetivo presentar algunas reflexiones sobre la consolidación del programa de cooperación y sus consecuencias sobre la recogida y uso de los fondos financieros para la educación y la finalización del Plan Nacional de Educación (PNE).

Palabras clave: Programa de Cooperación; Manifiesto de los Pioneros de la Nueva Educación, Financiamiento de la Educación.

\section{INTRODUÇÃO}

Nos anos vinte e trinta do século passado, um importante movimento de renovação educacional brasileiro culminou com a divulgação, ao povo e ao governo, do Manifesto dos Pioneiros da Educação Nova (1932). Historicamente, desde o Manifesto, lançado num contexto político e econômico conturbado e de grandes transformações, tem-se buscado estabelecer uma Política Educacional de Estado que se consolide para além dos mandatos governamentais.

Nesse contexto, em 1930 Getúlio Vargas ascendeu ao poder mediante processo revolucionário e lá permaneceu, em sua primeira gestão, pelo período de quinze anos. Era um período de crise mundial que repercutiu negativamente sobre a produção agrícola, na ruína de grandes fazendeiros e no aumento do desemprego nas grandes cidades. Como consequência, houve o crescimento de dificuldades financeiras para o país com a redução da receita das exportações e desvalorização da moeda nacional. Diante das dificuldades externas e sua repercussão no país e do propósito de Getúlio de reforçar o poder central, a Igreja Católica se assume como importante base de apoio ao governo (FAUSTO, 2010). Tal apoio influenciou diretamente as decisões que delinearam os rumos da educação pública brasileira.

Em movimento contrário e em defesa da escola pública laica e para todos, o Manifesto, nascido de um intenso movimento de intelectuais, pode ser considerado um documento de política educacional no qual se propõe a criação "de um amplo e abrangente Sistema Nacional de Educação pública abarcando desde a escola infantil até a formação dos grandes intelectuais pelo ensino universitário" (SAVIANI, 2010, p.253). O Manifesto traduz os anseios de uma corrente de educadores da Escola Nova que almejava a conquista da hegemonia educacional por meio da criação de um Sistema Nacional de Educação, considerando a diversidade da sociedade brasileira. Também, tanto no 
domínio da União quanto dos entes federados, caberia ao Estado responsabilizarse pela organização e acessibilidade de todos os cidadãos à escola por meio de financiamento da educação.

Considerando a grande relevância do documento para a educação e sua atualidade no sentido da construção de um Sistema Nacional de Educação, é oportuno apresentar algumas reflexões acerca de ações necessárias ao cumprimento do direito à educação, por meio da consolidação do regime de cooperação e sua repercussão no levantamento e uso dos fundos contábeis para a educação e da plena realização do II PNE.

\section{O MANIFESTO DOS PIONEIROS E SUA INFLUENNCIA SOBRE AS POLÍTICAS PÚBLICAS EDUCACIONAIS}

O Manifesto dos Pioneiros da Educação Nova de 1932 propunha uma reformulação da educação pública no país por meio de uma série de ações, dentre elas a criação de fundos vinculados a recursos de impostos. Esta e outras propostas auxiliaram na produção de uma política pública educacional, presente na Constituição de 1934 (XAVIER, 2002). Na página de abertura desse documento histórico, redigido por Fernando de Azevedo, encontra-se uma crítica da dissociação existente entre as reformas econômicas e as reformas educacionais, indicando-se a necessidade do entrelaçamento e encadeamento de ambas, dirigindo-as no mesmo sentido. Conforme Azevedo (1966a), reformas parciais, sem uma visão global dos problemas, geram desarticulação e fragmentação, inviabilizando sua realização.

O documento ressalta a gravidade do problema da educação como o principal dos problemas nacionais. Nele, destacam-se como princípios fundantes, de caráter filosófico, a escola essencialmente pública - destinada à época para crianças dos sete aos 15 anos - função primordial do Estado, a gratuidade, a obrigatoriedade - do Estado em oferecer, da família em matricular as crianças - evitando-se que a criança se ausente desse direito, a laicidade - evitando-se a influência de crenças ou disputas religiosas - a unicidade da escola pública acessibilidade a todos os cidadãos em idade escolar - a coeducação - destinada à meninos e meninas, conjuntamente. Como princípios organizacionais, de caráter social, destaca-se a unidade da função educacional, que constitui um novo programa de política educacional, a autonomia com corresponsabilidades - devendo abranger aspectos técnicos, administrativos e econômicos, desvinculada dos interesses políticos transitórios - e a descentralização - caráter nacional do sistema educacional, unidade sem uniformidade (SAVIANI, 2014).

No Manifesto destaca-se também, logo de início, que nem mesmo a 
política econômica poderia sobrelevar-se em importância à política de educação (AZEVEDO, 2010). Mostra-se, assim, a importância de se entrelaçarem e se encadearem as reformas econômicas e educacionais, de forma que sigam no mesmo sentido com vistas ao objetivo de construção de um sistema de educação atualizado com as demandas modernas de um país promissor. Nessa direção, parece-nos oportuno sublinhar que a organização de um Sistema Nacional de Educação, além da coerência interna que deverá possuir no sentido de facilitar a articulação entre as instâncias gestoras da educação nos planos nacional, regional e local, deverá ter mecanismos e aberturas para conexões mais amplas com a política de desenvolvimento do país.

Decorridos mais 80 anos de sua divulgação, ele continua atual frente aos desafios da educação nacional, desempenhando o papel de 'Manifesto Educador', para usar a expressão de Jorge Nagle (2014). O documento representa uma densa proposição histórica. Surgiu como um marco histórico, seguido por outros movimentos de forte representatividade, ocorridos posteriormente, que orientaram e influenciaram governos, mudanças nas legislações e nas políticas públicas de educação (ABICALIL, 2014).

Assim, com as mobilizações da sociedade em torno do II PNE, 2014/2024, vemos retomadas, atualmente, as discussões acerca das proposições feitas no Manifesto dos Pioneiros de 1932 em favor de uma escola pública, laica e para todos. Essa escola deverá ser garantida por meio do esforço comum entre os entes federados, conforme previsto na Constituição de 1988, em um consistente e responsável regime de cooperação, ainda em processo de consolidação no país.

Mais ainda. Estamos retomando a ideia de uma política de Estado para educação, conforme consta do Manifesto. No entanto, como ponderava Azevedo (1966b), a crescente complexidade das instituições e dos sistemas escolares, pressupõe grandes orçamentos. Nessa direção, importa considerarmos, ainda que de forma breve, a trajetória histórica do financiamento da educação pública.

\section{PERCURSO HISTÓRICO DO FINANCIAMENTO DA EDUCAÇÃO PÚBLICA NO BRASIL}

É na Constituição Federal de 1934, já sob a influência do Manifesto dos Pioneiros, que vamos encontrar o marco inicial da obrigatoriedade de atuação do Estado nas decisões e condução dos sistemas de ensino (CURY, 2007). Ao refazer um resgate histórico da previsão da oferta gratuita de educação pelo Estado, encontramos na Constituição Imperial de 1824 a educação primária como um direito, cabendo ao Império seu oferecimento. No entanto, seu financiamento se dá de forma precária por meio de adesão e de contrapartida. 
Durante o Império e no começo da Primeira República, foram muitas as tentativas de reformas que fracassaram. Com a aprovação da Reforma João Alves/Rocha Vaz pelo Decreto 16.780A, de 13 de janeiro de 1925 (UFSC, 2014), foi estabelecida a participação da União na organização do ensino primário, na reforma do ensino secundário e superior e na organização do Departamento Nacional de Ensino. Ficou estabelecido o financiamento da educação, com divisão de atribuições entre Estados e União, destinado ao pagamento e oferecimento de residência a professores em escolas rurais, ao oferecimento de espaço físico para as escolas e material didático (CURY, 2007). Essa reforma, promulgada ao tempo em que começava a ganhar força o movimento de renovação educacional nas décadas de 1920 e 1930 do século passado já representava um pequeno avanço em relação à responsabilidade da União, sobretudo com referência à educação básica.

A forte influência exercida pelo movimento dos educadores, que teve seu ponto mais alto com a divulgação do Manifesto dos Pioneiros em 1932, com ativa participação de grandes nomes relacionados à educação, como Anísio Teixeira, Fernando de Azevedo eLourenço Filho, dentre outros, repercutiu na Constituição de 1934, numa primeira vinculação de parte da arrecadação dos impostos. Surgida “do entrechoque de tendências e interesses, manifestados em sucessivos documentos e em inúmeras emendas apresentadas à reflexão dos constituintes" (VILLALOBOS, 1969, p.14), representou uma vitória dos ativos educadores da Associação Brasileira de Educação e de seu Manifesto dos Pioneiros da Educação Nova.

$\mathrm{Na}$ Constituição de 1934, ficam estabelecidas para todos os entes federados a obrigatoriedade e gratuidade do ensino primário. Conforme prevê seu artigo 156, no capítulo destinado à educação e cultura, fica estabelecido que a União e os Municípios aplicarão nunca menos de dez por cento e os Estados e o Distrito Federal nunca menos de vinte por cento da renda resultante dos impostos na manutenção e no desenvolvimento dos sistemas educativos (BRASIL, 2014a).

Todavia, os ventos autoritários que chegavam da Europa, oriundos do nazifascismo, concorreram fortemente para que, em 1937, fosse promulgada nova Constituição, que instituiu o Estado Novo. Essa nova Constituição suprimiu a vinculação de 1934 e, desde então, a garantia de mais recursos vinculados à educação passou a oscilar conforme a direção dos regimes políticos, ou seja, ora rumo à democracia, ora, à ditadura.

Com o fim da $2^{a}$ Guerra mundial e da ditadura Vargas, a nova Constituição, de 1946, pós-Estado Novo, retoma a vinculação de impostos para o financiamento da educação e possibilita a elaboração do Projeto de Lei de Diretrizes e Bases da Educação Nacional, enviado ao Congresso Nacional em 1948, ondepermaneceupor vários anos sob os efeitos de manobras legislativas de protelação. Ao ser retomado na segunda metade da década de 1950, com a apresentação do Substitutivo do 
Deputado Carlos Lacerda, dá origem a um histórico debate entre os defensores da escola pública e os defensores da escola particular, que teve seu ponto culminante com o Manifesto Mais Uma Vez. Convocados, de 1959, mais uma vez, redigido por Fernando de Azevedo, desta vez assinado não mais por 24 pioneiros de 1932, mas por 161 educadores, cientistas, intelectuais e líderes formadores de opinião.

O Manifesto de 1959 reafirma a importância de organizar a educação nacional no marco da doutrina federativa e faz duras críticas ao crescimento desordenado da educação, concomitante à redução da ação coordenadora do poder público, federal e estadual. Entre as três posições que se debatiam na época, a do monopólio do Estado, a de liberdade total e a de liberdade disciplinada, o Manifesto faz uma opção pela última, afirmando mesmo "pela liberdade disciplinada é que somos" (AZEVEDO, 2010, p.87). Um parêntese se torna necessário. A ideia de "liberdade disciplinada" defendida pelo Manifesto de 1959 respeitava, por um lado, a autonomia dos Estados, do Distrito Federal e dos Municípios e, por outro, reafirmava a importância da ação coordenadora do poder público, considerando-a fundamental para a organização do Sistema Nacional de Educação.

Em 1961 é, então, estabelecida a primeira Lei de Diretrizes e Bases da Educação Nacional (LDB 4.024/61). Dela constam os fundamentos norteadores, estruturas previstas e a normatização do sistema educacional brasileiro. Também a vinculação de impostos à educação permanece e se amplia; "cada nível de ensino contaria com um Fundo, cuja elaboração estaria a cargo do Conselho Federal de Educação" (CURY, 2007, p. 837). Ao Conselho caberia a tarefa de deliberar sobre o ensino primário, médio e superior. Com a criação dos Conselhos Estaduais de Educação, organizados por leis estaduais, conforme previsto no Art. $10^{\circ}$ da LDB, buscou-se atender às demandas educacionais dos Estados, de suma importância na história da cooperação federativa. Em 1962, o Conselho Federal de Educação, instituído na recente LDB/61, entregou ao MEC o primeiro Plano Nacional de Educação que, desde essa época, já estabelecia objetivos e metas qualitativas e quantitativas para um período de oito anos. Esse plano foi coordenado por Anísio Teixeira e destacava o imperativo de implementação articulada entre a União, os Estados, o Distrito Federal e os Municípios. Todavia, com o golpe militar de 1964 e a instauração de nova ditadura, o plano concebido por Anísio em 1962 perdeu muito de suas dimensões mais substantivas, sobretudo em relação ao pressuposto da cooperação federativa.

Apesar dos reveses, foi criado em 64, regulamentado em 65 e alterado em 66 o salário educação ${ }^{1}$, um novo mecanismo de financiamento de programas, projetos e ações com potencial de trazer mais recursos à ampliação do ensino.

1 O salário educação provém de uma contribuição compulsória das empresas e entidades públicas e privadas vinculadas ao Regime Geral da Previdência Social (FNDE, 2014). 
Essa aplicação foi determinada por lei na qual a divisão prevista entre União e estados buscava equilibrar as diferenças regionais (CURY, 2007). No entanto, apesar dessa nova fonte de recursos, em relação à educação básica, o período dos militares, diferentemente do que aconteceu com respeito à educação superior e à pós-graduação, pode ser considerado desastroso.

Somente com a Emenda Calmon, de 1983, e sua regulamentação em 1985 é que a vinculação volta a ser estabelecida. Essa emenda estabelece, para a manutenção e desenvolvimento do ensino, a aplicação anual e obrigatória da União, de nunca menos de treze por cento, e dos Estados, Municípios e Distrito Federal, de no mínimo vinte e cinco por cento da renda resultante dos impostos.

Finalmente, com a Constituição de 1988, a educação é apontada como o primeiro dos direitos sociais e afirmada, por diversas maneiras, como dever do Estado: na consagração do Ensino Fundamental como direito público e subjetivo, na oferta progressiva do Ensino Médio obrigatório, na vinculação do financiamento da educação aos fundos e em programas suplementares de alimentação e saúde.

O direito à educação perpassa por uma sequência de acontecimentos históricos no Brasil, inscritos tanto na aprovação de leis, quanto na ocorrência de movimentos em favor da garantia do acesso e permanência a uma escola pública para todos. Nesse sentido, a constituição de 1988 representou grande avanço na concepção do direito à educação, sendo-lhe dedicado um capítulo inteiro. Nele, foram previstos "aumento dos percentuais de vinculação de recursos, a gestão democrática, padrões mínimos de qualidade e equidade, pluralismo de ideias, piso salarial docente, universalização do Ensino Fundamental, dentre outros" (CUNHA, 2013, p.43).

Em matéria de direito à Educação, a Constituição Cidadã de 1988, intitulada Constituição Ulysses Guimarães, promoveu mudanças sem precedentes na história da educação brasileira. A partir dela, a Educação passou a contar com dispositivos constitucionais que, juntamente com a continuidade de mobilizações e esforços de diversos setores da sociedade, objetivam um sistema de educação pública de qualidade. Nesse sentido, contribuíram e ainda contribuem para o avanço do direito à Educação "entidades científicas de docentes e pesquisadores, sindicatos e entidades da sociedade civil" (Idem, p.45), inclusive impedindo que pudessem prosseguir, junto ao setor legislativo, propostas inadequadas para a educação. Somando-se a isto, atuam os operadores jurídicos, representados pela Associação Brasileira de Magistrados, Promotores de Justiça e Defensores Públicos da Infância e da Juventude, discutindo e apontando soluções, mesmo que de forma singular, para o cumprimento do direito à Educação e alargando o "espaço de atuação das instâncias de Justiça no campo educacional".

A entrada em cena dos operadores de justiça, exigindo dos entes federados 
o cumprimento das normas legais do direito à educação, contribuiu para ampliar as discussões em termos de suas competências. Nesse sentido, também devem ser destacadas a criação do Conselho Nacional dos Secretários de Educação (Consed) e da União Nacional dos Dirigentes Municipais de Educação (Undime), entidades colegiadas que passaram a ter relevante papel na discussão do regime de cooperação.

A partir de então, em 1994, na Conferência Nacional de Educação para Todos, emergiu o Pacto pela Valorização do Magistério e Qualidade da Educação. O pacto foi assinado, ainda no mesmo ano, por representantes do Ministério da Educação e por dirigentes de entidades educacionais e veio atender uma reivindicação histórica dos professores da rede pública de educação básica ao definir e estabelecer um piso salarial nacional. A proposta de criação de um piso salarial nacional só tornou-se lei em 2008, após longa tramitação no Congresso Nacional.

No ano de 1996, nossa segunda LDB (Lei 9394) foi aprovada e, entres outros, teve o mérito de formalizaro papel dos estados na articulação e coordenação das políticas estaduais de educação. Em outras palavras, o estado não deveria mais restringir sua atuação somente às redes por ele mantidas, mas estendê-la a todas as instituições escolares existentes na unidade federada. Logo em seguida, uma emenda constitucional instituiu o Fundo de Manutenção e Desenvolvimento do Ensino Fundamental e de Valorização do Magistério (FUNDEF), que representou notável e estruturante avanço no regime de cooperação, pois a lógica de criação desse mecanismo contábil foi permitir que o dinheiro fosse para onde estivesse matriculado o aluno, nas redes municipais ou estaduais. Em 2001, foi aprovado pelo Congresso Nacional o PNE. Nele, foram estabelecidas metas possíveis de serem alcançadas a partir do acesso, permanência e qualidade da educação. Esse plano, em sua concepção original, sinalizou algumas divisões de responsabilidades para a consecução das metas estabelecidas. Entretanto, o veto presidencial ao aumento dos investimentos para 7\% do PIB, aprovado pelo Congresso Nacional, inviabilizou o cumprimento da maior parte de suas metas, notadamente as referentes à qualidade. Dessa forma, sublinhou Cury (2007, p.839), sem o aumento de recursos previstos, o PNE caracterizouse como mais um "ato declaratório". No ano de 2006, a Emenda Constitucional n 53 criava o Fundo de Manutenção e Desenvolvimento da Educação Básica e de Valorização dos Profissionais de Educação (FUNDEB), em substituição ao FUNDEF, ampliando-o de forma a possibilitar o financiamento não apenas do Ensino Fundamental, mas de toda a Educação Básica. Além disso, o FUNDEB ampliou a participação da União no financiamento da Educação Básica, medida de inegável alcance para o regime de cooperação e, também, para o projeto do Sistema Nacional de Educação (ABICALIL, 2014). Mais recentemente, com o FUNDEB e o PNE 2014, busca-se recuperar alguns 
aspectos do Pacto de Valorização do Magistério e Qualidade da Educação.

Assim, após concisa trajetória histórica do financiamento público da educação brasileira e da relevância dos sujeitos e entidades a ela relacionados, faz-se necessário retomar as discussões sobre a questão da cooperação federativa e da colaboração entre sistemas para que os planos e metas delimitados sejam alcançados e haja uma articulação entre todos os entes federados por meio de um Sistema Nacional de Educação ajustado ao PNE assim como à realidade e diversidades de cada região.

\section{RELAÇÃO DOS FUNDOS DE MANUTENÇÃO DA EDUCAÇÃO COM O PNE}

O FUNDEF, criado em 1996, trouxe de volta recursos que vinham sendo aplicados em outras chancelas, devido, sobretudo, a ausência de articulação entre as redes estaduais e municipais de educação, como também possibilitou um avanço significativo na cooperação entre os entes federados. Esse fundo era composto por recursos provindos de uma variedade de impostos arrecadados, dos quais, eram destinados 15\% à denominada Cesta Fundef. Dada sua complexidade e caráter multidisciplinar, o advento do Fundef conduziu à necessidade de articulação e planejamento conjunto entre as políticas de educação dos estados e dos municípios, abrindo espaços de diálogo entre as redes e contribuindo para romper o isolamento e falta de diálogo entre essas instâncias.

Nesse sentido, algumas ações promoveram os avanços progressivos do regime de cooperação e preparação para o advento de um Sistema Nacional de Educação. A evolução do Fundef para Fundeb, em 2006 e, em seguida, a formulação e institucionalização do Plano de Desenvolvimento da Educação (PDE), em 2007, configuram-se como avanços importantes da doutrina federativa no campo da educação. Ambos ajudaram a instauração de uma visão mais sistêmica da educação e possibilitaram a criação de vários mecanismos, como o Plano de Ações Articuladas (PAR), conforme Decreto no 6.094 de 2007, e o programa Mais Educação, instituído pela Portaria interministerial no 17/2007 e regulamentado pelo decreto $\mathrm{n}^{\circ}$ 7.083/2010 estimulando a ampliação da jornada escolar e a estruturação curricular na perspectiva da Educação Integral, que deram início a uma nova etapa de compromisso da União com os demais entes federados.

O PDE, é necessário reconhecer, foi o mais importante plano da educação nacional, até os dias atuais. Além de salvar o I Plano Nacional de 
Educação (PNE) ${ }^{2}$, ele teve o mérito de preparar o advento do II PNE. A partir de então, com o PNE e sua constituição de fundos contábeis para o financiamento da educação, destaca-se a "necessidade de efetivação do federalismo cooperativo por meio de um aperfeiçoamento contínuo do sistema de colaboração entre os sistemas de ensino e entes federados" (MARTINS, 2011, p.17).

O PNE oportuniza o planejamento integrado e colaborativo de ações entre entes federados. Com isso, espera-se que estados e municípios assumam esse compromisso considerando todas as etapas, níveis e modalidades da educação por meio de ações cooperativas entre si e com o apoio federal. Sua elaboração deve ocorrer por iniciativa do MEC, em regime de cooperação. Dessa forma, consolida-se a função redistributiva e supletiva da União em relação aos outros entes federados (CURY, 2010). Ademais, a sua perspectiva de elevar os investimentos para $10 \%$ do PIB até o final de sua implementação, em 2024, se concretizada e seguida de processos de gestão profissionalizados, configurarse-á, do ponto de vista histórico, como o evento mais importante da história das políticas educacionais do país.

Um plano de educação está permeado do pensamento político-ideológico de cada governo, sendo importante instrumento técnico para sua concretização. Como observou Fonseca (2013), os planos no Brasil oscilaram, tendo, por vezes, um caráter utilitarista, voltados ao crescimento econômico e, em outros momentos, de caráter social e valorativo. No caso do II PNE, que passou por um processo de construção coletiva e, no âmbito do Congresso Nacional, por mais de três anos foi objeto de várias discussões e emendas, ele alia demandas de caráter mais utilitarista a demandas mais sociais. A elaboração do II PNE coincidiu com o maior período de inclusão social na educação brasileira. Sua implementação exigirá novos avanços da doutrina federativa. E, para que isso aconteça, ele precisará ser conduzido como política de Estado, requerendo do poder político sensibilidade, talento e responsabilidade para com o futuro do país.

É certo que as metas estabelecidas em um plano encontram dificuldades de se estabelecerem em tempo e espaço previstos. Isso ocorre devido aos imprevistos e oscilações de toda ordem. Quando um plano de educação se estende a todo o território nacional, lida com divergências entre estados e municípios, dadas diferenças regionais e estruturais. Para manter suas propostas de um projeto comum para a sociedade brasileira, o Estado se vale de seu poder de barganha, por vias de financiamento e do fortalecimento da democracia, por

2 Como se trata de um documento norteador para a educação pública nacional, é preciso que todos os integrantes da escola (gestores, professores, funcionários, estudantes, pais e comunidade) e sociedade civil, dele tenham conhecimento e participem da elaboração de seus planos de educação, considerando suas especificidades e demandas próprias e contribuindo para o alcance das metas e da oferta de uma educação pública de qualidade (BRASIL, 2014c). 
meio do diálogo (FONSECA, 2013).

Daí, a importância de alguns dispositivos incluídos no II PNE, sobretudo os que se referem à criação de instâncias permanentes de negociação e cooperação entre a União, os Estados, o Distrito Federal e os Municípios, como também instâncias de pactuação e negociação em cada estado. Esses dispositivos, se devidamente implementados, poderão, em médio prazo, promover avanços da cooperação federativa, tanto no plano nacional quanto no estadual. Também, os arranjos de desenvolvimento da educação constituem alternativas para a formulação de políticas estaduais de educação integradas e acima de interesses político-partidários.

No processo de implementação do II PNE, importa considerar as colocações de Martins (2011), no sentido de que o equilíbrio do pacto federativo, definido por competências tributárias dos entes federados e dos encargos ou serviços públicos a serem por estes oferecidos, depende da distribuição de competências na esfera da educação. Sob esse aspecto, a estratégia lançada pelo MEC em meados de 2014, por intermédio da Secretaria de Articulação com os Estados e Municípios (SASE), sob o título Planejando a Próxima Década definiu uma agenda de construção coletiva dos planos decenais dos estados e dos municípios. Se essa estratégia não sofrer solução de continuidade, poderá gradualmente definir competências tributárias e pedagógicas que darão maior clareza às responsabilidades de cada ente federado.

Essa estratégia do MEC salientou em sua apresentação um dos pontos capitais do planejamento educacional no Brasil, qual seja a necessidade de os gestores da educação de todas as instâncias irem além de uma visão restrita à sua rede e ao tempo de sua gestão, de forma a incentivar a colaboração entre os sistemas para a elaboração de metas comuns. Essa nova atitude poderá converterse em etapa importante para a instituição do Sistema Nacional de Educação (BRASIL, 2014c). Esses fatos convergem para o debate e consolidação de um regime de cooperação responsável e ativo na garantia do direito à educação de qualidade.

\section{REGIME DE COOPERAÇÃO: CAMINHOS TRILHADOS E EXPERIÊNCIAS}

A Constituição brasileira, ao instituir o Estado Democrático, assegura o exercício dos direitos sociais e individuais, assim como o bem-estar de todo o povo brasileiro. Em seu artigo 23 encontram-se previstas ações, de competência comum aos entes federados, que constituem o regime de cooperação, com vistas a proporcionar meios de acesso à cultura, à educação e à ciência, dentre outros. $\mathrm{O}$ 
regime de cooperação é, pois, uma ação intergovernamental destinada a garantir a distribuição de recursos financeiros aos entes federados e entre eles.

Em sua forma de atuação, o regime de cooperação pode ocorrer em duas dimensões: verticalmente (entre União, Estados, Municípios e Distrito Federal) e horizontalmente (entre municípios e entre Estados). Contudo, apesar do forte apelo e respeito às estruturas hierárquicas já conhecidas, a articulação vertical deve ser vista como processo interrelacional entre os entes federados, mediado e articulado pelo constante diálogo e orientado por princípios de cooperação recíproca. Assim sendo, o objetivo do regime de cooperação prevê a superação de possíveis competições entre os entes federados em diversos níveis como, por exemplo, no caso da cobrança e isenção de impostos (OLIVEIRA; GANZELI, 2013).

Com vistas à minimização de problemas referentes ao financiamento da educação pública, outras modalidades de articulação podem ocorrer interinstitucionalmente nos municípios, nos Estados e com a União, e, também, por meio de parcerias do setor privado com a comunidade. Muitas dessas ações, por se tratar de iniciativas de políticas de governo e não de Estado, são muito pontuais e correm o risco de descontinuidade. Dessa forma, os fundos para a educação, os convênios, os consórcios públicos, os arranjos de desenvolvimento da educação e outras experiências associativas constituem algumas das diferentes possibilidades de parcerias, frequentemente adotadas pelos municípios para solucionar tais problemas.

A existência de outras experiências associativas entre a esfera local e estadual e, entre municípios vizinhos, constitui-se de ajustes próprios, criados por demandas comuns de determinadas regiões ou municípios. É o caso de municípios conurbados, nos grandes centros e de fronteira, inclusive os pertencentes a países vizinhos; também, de programas desenvolvidos em rede mundial como o Programa Cidades Educadoras (OLIVEIRA; GANZELI, 2013).

Atualmente, as relações estabelecidas entre os entes federados se diferenciam das de outrora, dadas as condições políticas, financeiras e de implementação. Por haver mecanismos financeiros de transferência entre os Estados, os Municípios, o Distrito Federal e a União, a tarefa de mediar esses mecanismos ficou destinada à União.

O regime de cooperação reafirmou então as responsabilidades das esferas governamentais no cumprimento do direito à educação. A União promoveu o estreitamento de relações entre os entes federados por meio de ações diversas como, por exemplo, programas voltados para o fortalecimento da esfera municipal cujo foco eram os dirigentes municipais e conselheiros municipais de educação (VIEIRA; VIDAL, 2013). 
Dentre essas ações, destacam-se os Arranjos de Desenvolvimento da Educação (ADE) que, após definições do Conselho Nacional de Educação, caracterizam-se como novas alternativas frente às formas de cooperação já existentes entre entes federados. Com eles, busca-se promover a troca de experiências e dar soluções a problemas comuns de um grupo de municípios próximos com características socioeconômicas comuns (VIEIRA; VIDAL, 2013). Essa ação prevê a articulação entre os Estados e a União, fortalecendo, assim, o planejamento integrado e colaborativo entre essas instâncias.

Os arranjos de desenvolvimento da educação constituem ações horizontais de cooperação entre os estados e os municípios. Foram almejados com o intuito de promover a troca de experiências e busca por soluções de problemas comuns entre os entes federados. Nesse sentido, o movimento Todos pela Educação é um forte apoiador desses arranjos, nos quais a participação de empresas e fundações é um dos importantes pilares.

Devido à urgência de cooperação entre as unidades federadas e os municípios na garantia e efetivação dos direitos sociais, tal participação tornase de grande importância. No entanto, como esclarece Araújo (2012), o apadrinhamento de escolas por empresas privadas pode imprimir em sua prática administrativo-pedagógica um modelo de gestão empresarial que descaracteriza a principal função da escola que é educar cidadãos. Os arranjos são uma maneira paliativa de resolver problemas onde o Estado ou setores responsáveis ainda não alcançam.

Por se tratar de uma construção histórica, a cooperação, leva algum tempo para se efetivar. Para que as ações empreendidas tenham êxito, são necessárias confiança e ação mútua entre as partes envolvidas. Vieira e Vidal (2013) citam, como exemplo, experiências de cooperação que, articuladas a questões territoriais e econômicas, deram certo em três estados brasileiros: Rio Grande do Sul, Mato Grosso e Ceará.

O regime de cooperação pode, em sua essência, manter uma estrutura hierarquizada (com deliberações do centro para a periferia - das capitais para os municípios) ou podem dar-se de forma negociada (entre municípios vizinhos e entre os municípios e o Estado). A experiência do Rio Grande do Sul, ocorrida na década de 90 entre municípios com porte semelhante e em âmbito regional e estadual, promoveu significativos avanços na qualidade e democratização da escola pública, chamando, assim, a atenção da comunidade acadêmica para estudos, pesquisas e publicações diversas. A cooperação intermunicipal ocorreu por meio de um trabalho colaborativo e de intercâmbio de experiências (LUCE; SARI, 2010).

No caso do Ceará, Vieira e Vidal (2013) destacam o longo e contínuo 
processo de aproximação e negociação havido entre as partes interessadas: governo estadual e governos municipais. O motivo dessa aproximação foi o enfrentamento direto das condições de pobreza que o Estado apresentava, que, para tal, demandou atuação em conjunto e disposição permanente das partes envolvidas e, também, da continuidade do processo, por tratar-se de programas de governo e não de Estado.

A experiência do Ceará, assim como de outros Estados e Municípios brasileiros, exemplifica que a consolidação do regime de cooperação horizontalizado entre municípios e, mais amplamente, entre estados, demanda confiança mútua e regulamentação de proposições e ações para sua continuidade. É um processo lento e que necessita da firmeza de propósitos dos governantes e intensa participação da sociedade frente às demandas sociais, com o objetivo de efetivar os direitos sociais, especificamente a educação.

\section{CONSIDERAÇÕES FINAIS}

Passados mais de oito décadas do Manifesto dos Pioneiros de 1932 e aprovado novo Plano Nacional de Educação, 2014-2024, o Brasil, apesar de progressos importantes que se efetivaram, ainda se ressente das omissões do passado. Sob esse aspecto, torna-se ousado o desafio do II PNE, que terá de fazer em poucos anos o que deixou de ser feito desde, pelo menos, o Manifesto de 1932. A ausência de responsabilidades claras entre os entes federados tem contribuído para a fragilização de políticas, em boa parte das unidades federadas. Sobressai a imperiosa necessidade de planejamentos integrados e de gestões que se movimentem preponderantemente na direção da melhoria do ensino conforme estabelecido pelo II PNE.

Acreditamos que o Sistema Nacional de Educação, por meio da consolidação do II PNE, conforme vislumbrado pelos Pioneiros da Educação Nova, encontre na participação da sociedade civil, seu principal aliado. Que os conselhos criados para acompanhamento dos recursos destinados à educação sejam estimulados, respeitados e fortalecidos. Que seus representantes tenham o reconhecimento devido de suas funções para que os gestores públicos ajam com mais responsabilidade e garantam a educação pública de qualidade, tão sonhada há mais de 80 anos. Também, que os operadores jurídicos estejam atentos ao cumprimento do direito à educação pública de qualidade, atendendo a sociedade como um todo, de forma plural.

Certamente, será importante considerar que um Sistema Nacional de Educação passa por uma discussão com vários segmentos da sociedade civil. Seus contornos podem gerar polêmicas e reacender velhas batalhas. Daí, a importância 
de visão e talento político na condução de seu processo de construção.

Para finalizar, importa considerar que o regime de cooperação está sendo construído aos poucos, de forma gradual, conforme permite a condução política do país com base na coligação de forças heterogêneas. Desde os avanços da reforma Rocha Vaz, passando pelo brado do Manifesto dos Pioneiros, a promulgação da Constituição de 1934, o retrocesso da Constituição de 1937, a retomada de 1946, a luta pela primeira LDB, a primeira LDB, o plano de Anísio de 1962, o plano trienal de 1963, o retrocesso do golpe com as constituições de 1967 e 1969, o projeto Carlos Pasquale do salário educação, a Emenda Calmon, a Constituição de 1988, o Pacto pela Valorização do Magistério, o Fundef, o Fundeb, o I PNE e o PDE 2007, as Emendas 53 e 59, até chegar ao II PNE, 2014/2024, com a instituição de uma instância de negociação, podemos perceber uma grande evolução do financiamento da educação pública brasileira. Nessa evolução, precisam ser valorizados os arranjos e experiências, municipais e estaduais, pois, dos avanços que se registrarem no âmbito das unidades federadas, dependerá, em grande parte, o próprio avanço do Sistema Nacional de Educação.

\section{REFERÊNCIAS}

ABICALIL, Carlos Augusto. O sistema nacional de educação: a atualização do manifesto de 80 anos. In BRASIL. O Sistema Nacional de Educação: diversos olhares 80 anos após o Manifesto. Brasília: MEC/SASE, 2014.

ARAÚJO, Gilda Cardoso. Federalismo cooperativo e arranjos de desenvolvimento da educação: o atalho silencioso do empresariado para a definição e regulamentação do regime de cooperação. In Revista brasileira de política e administração da educação. V.28, n.2 (p.515-531).Recife: ANPAE, 2012.

AZEVEDO, Fernando de; et al. Manifesto dos pioneiros da educação nova (1932) e dos educadores (1959). Recife: Fundação Joaquim Nabuco, Ed. Massangana, 2010.

A educação e seus problemas (tomo I). São Paulo: Melhoramentos, 1966a.

A educação entre dois mundos. São Paulo: Melhoramentos, 1966b.

BRASIL. Constituição da República dos Estados Unidos do Brasil (de 16 de julho de 1934). Disponível em: http://www.planalto.gov.br/ccivil_03/constituicao/ constituicao34.htm Acesso em: 14 dez. 2014a. 
BRASIL, MEC. Conselho Nacional de Educação. Disponível em: http:// portal. mec.gov.br/index.php? Itemid $=754 \&$ catid $=323 \% 3$ Aorga os vinculados\&id $=14306 \% 3$ Acne-historico\&option $=$ com_content\&view $=$ article Acesso em 09/09/2014b.

BRASIL, MEC/SASE. Planejando a próxima década: conhecendo as 20 metas do Plano Nacional de Educação. Disponível em: www.pne.mec.gov.br/pdf/pne_ conhecendo ᄀ_20_metas.pdf. Acesso em 06/10/2014c.

CUNHA, Célio. Justiça pela inclusão e qualidade na Educação. In ABMP, Todos pela educação (org.). Justiça pela qualidade na educação. São Paulo: Saraiva, 2013.

CURY, Carlos Roberto Jamil. Estado e políticas de financiamento em educação. Educação e sociedade. Campinas v.28 n.100-Especial p.831-855 out.2007.

A questão federativa e a educação escolar (149-168). In OLIVEIRA, Romualdo Portela; SANTANA, Wagner (orgs.). Educação e federalismo no Brasil: combater as desigualdades, garantir a diversidade. Brasília: UNESCO, 2010.

FAUSTO, Boris. História concisa do Brasil. São Paulo: Editora Universidade de São Paulo, 2010.

FNDE. Salário educação. Disponívelem:http://www.fnde.gov.br/financiamento/ salario-educacao/salario-educacao-entendendo-o Acesso em 10 set. 2014.

FONSECA, Marília. Planejamento educacional no Brasil: um campo de disputas entre as políticas de governo e as demandas da sociedade. In: FERREIRA, Eliza Bartolozzi e FONSECA, Marília (Orgs.). Política e planejamento educacional no Brasil do século 21. Brasília: Liber Livro, 2013.

LUCE, Maria Beatriz; SARI, Marisa Timm. O regime de colaboração na educação do Rio Grande do Sul. In: PORTELA, Romualdo e SANTANA, Wagner. Educação e Federalismo no Brasil: combater as desigualdades, garantir a diversidade. Brasília: UNESCO, 2010.

MARTINS, Paulo de Sena. FUNDEB, Federalismo e regime de colaboração. Campinas, SP: Autores Associados, 2011.

NAGLE, Jorge. Educação e sociedade na primeira República. São Paulo: Editora Universidade de São Paulo, 2014.

NETO, Lira. Getúlio: do governo provisório à ditadura do Estado Novo. São 
Paulo: Companhia das Letras, 2013.

OLIVEIRA, Cleiton; GANZELI, Pedro. Relações intergovernamentais na educação: fundos, convênios, consórcios públicos e arranjos de desenvolvimento da educação. In Educação e Sociedade: revista de ciências da educação. Vol. 34, n. 125 (p.1031-1047). Campinas, SP: CEDES, 2013.

SAVIANI, Demerval. O Manifesto dos Pioneiros da Educação Nova de 1932 e a questão do Sistema Nacional de Educação. In BRASIL. O Sistema Nacional de Educação: diversos olhares 80 anos após o Manifesto. Brasília: MEC/ SASE, 2014.

. História das ideias pedagógicas no Brasil. Campinas, SP: Autores Associados, 2010.

UFSC, https://repositorio.ufsc.br/bitstream/handle/123456789/104707/1925_ Decreto $\% 2016782$ A_13\%20de $\% 20$ janeiro.pdf ? sequence $=1 \&$ is Allowed $=\mathrm{y}$ Acesso em 20 dez.2014.

VIEIRA, Sofia; VIDAL, Eloísa. Construindo uma história de cooperação na educação: a experiência do Ceará. In Educação e Sociedade: revista de ciências da educação. Vol. 34, n. 125 (p.1075-1093). Campinas, SP: CEDES, 2013.

VILLALOBOS, João Eduardo Rodrigues. Diretrizes e bases da educação: ensino e liberdade. São Paulo: Editora Universidade de São Paulo, 1969.

XAVIER, Libânia Nacif. Para além do campo educacional: um estudo sobre o Manifesto dos Pioneiros da Escola Nova. Bragança Paulista: Edusf, 2002.

CÉLIO DA CUNHA é professor do Programa de Mestrado e Doutorado em Educação da Universidade Católica de Brasília (UCB). Doutor em Educação pela Universidade Estadual de Campinas (UNICAMP). E-mail:celio.cunha@brturbo. com.br

LUCIANA C. LIMEIRA é professora da Secretaria de Estado de Educação do Distrito Federal (SEE/DF). Doutoranda em Educação pela Universidade Católica de Brasília (UCB). E-mail: lucianaclimeira@gmail.com

Recebido em abril de 2015

Aprovado em agosto de 2015 